\title{
Improving quality of home-based postnatal care by microteaching of multipurpose workers in rural and urban slum areas of Chandigarh, India: a pilot study
}

\author{
This article was published in the following Dove Press journal: \\ Advances in Medical Education and Practice \\ 19 December 2016 \\ Number of times this article has been viewed
}

\author{
Madhu Gupta' \\ Jaya Prasad Tripathy ${ }^{2}$ \\ Limalemla Jamir ${ }^{3}$ \\ Ashutosh Sarwa ${ }^{3}$ \\ Smita Sinha ${ }^{3}$ \\ Chering $\mathrm{Bhag}^{3}$ \\ 'Department of Community \\ Medicine, School of Public Health, \\ Post Graduate Institute of Medical \\ Education and Research, Chandigarh, \\ ${ }^{2}$ Department of Operational \\ Research, International Union \\ Against Tuberculosis and Lung \\ Disease, The Union South East Asia \\ Office, New Delhi, ${ }^{3}$ Department \\ of Community Medicine, School \\ of Public Health, Post Graduate \\ Institute of Medical Education and \\ Research, Chandigarh, India
}

\begin{abstract}
Background: Microteaching is an efficient teaching tool to improve skills. Until now, its use is very limited in the health sector. A pilot study was carried out to improve the quality of homebased postnatal care by microteaching of health workers (HWs) and ascertain its feasibility for supportive supervision.
\end{abstract}

Methods: All $(\mathrm{n}=12)$ the HWs catering to a population of $\sim 0.1$ million were video recorded while performing home-based postnatal check up in Chandigarh from August 2013 to December 2014. After each round, HWs were shown their videos and trained in the facility and at home. Video recordings, assessments followed by training, continued until HWs acquired the intended skills. A pretested structured checklist based on the national home-based postnatal care guidelines was used for recording and assessing of postnatal skills. A score " 0 " given for no task, "1" for incorrectly done or partially done task, and " 2 " for correct task. The average score of each round was calculated and compared.

Results: The overall skill assessment score improved from 0.64 to 1.76 , newborn examination skill from 0.52 to 1.63 , maternal examination from 0.54 to 1.62 , and counseling from 1.01 to 1.85 after three rounds of video recording. The proportion of HWs carrying a thermometer increased from $21 \%$ to $100 \%$. Second and third rounds of video recording and microteaching were successfully carried out by the program supervisors.

Conclusion: This was the first study to report on the effective use of microteaching in improving home-based postnatal care skills of the health care workers and its feasibility for supportive supervision.

Keywords: microteaching, multipurpose health worker, nursing, home-based postnatal care, HBPNC, video recording, ANM, ASHA

\section{Introduction}

India has a high infant mortality rate of 40/1,000 live births and maternal mortality ratio of 178 per 100,000 live births. ${ }^{1-2}$ To reduce the infant mortality rate and maternal mortality ratio, much emphasis is laid on home-based postnatal care for early detection of complications during neonatal period and puerperal period so that early referral and treatment could be initiated to prevent mortality. Currently, auxillary nurse midwives (ANMs) and accredited social health activists (ASHAs) are given training to provide home-based postnatal care in India. ${ }^{3}$ The services rendered by them are mostly skillbased and the quality and outcome of services depend a lot on the skills acquired during training. ASHAs are trained in these skills through four rounds of training of 5 days
Correspondence: Madhu Gupta Department of Community Medicine, School of Public Health, Post Graduate Institute of Medical Education and Research, Chandigarh 160012, India $\mathrm{Tel}+919914208226$ Fax +9I I72 2744401 Email madhugupta21@gmail.com 
each in a year using modules 6 and $7 .^{3}$ ANMs are trained for 8 days under the Integrated Management of Newborn and Childhood Illnesses training. ${ }^{4}$ However, skills acquired in these trainings tend to be forgotten if not practiced routinely and left unsupervised. ${ }^{5}$

Microteaching is an effective method for skill enhancement under skilled supervision and constructive feedback. It involves the steps of "plan, teach, observe, re-plan, reteach and re-observe."6 It is a technique whereby activities performed by the trainees are observed by the supervisor who gives useful feedback with arguments and reasons. The supervisor draws the attention of the trainees to the points where they could not perform well. In the light of the feedback, the trainees replan the session in order to demonstrate the skill in a more effective manner in the second round. These rounds may be repeated several times till adequate mastery level is achieved. The sessions may be video recorded and later displayed to them so as to identify their weaknesses and strengths for better skill building. Studies have reported the use of microteaching technique for skill enhancement but its scope has been mainly concentrated in teaching. ${ }^{7,8}$ It allows the trainees to learn through manipulative experience and receive immediate feedback regarding their performance. ${ }^{9}$ Gordon and Pace have reported its effectiveness in enhancing communication skills in business communication. ${ }^{10}$ In the health sector, use of audiovisual aid has been known to enhance the transfer of skills efficiently in neonatal resuscitation training programs in rural hospitals. ${ }^{11}$ Studies have demonstrated the effectiveness of microteaching as an effective training strategy compared to conventional training methods in only a fifth of the time and with fewer administrative problems. ${ }^{12}$ In another study, participants reported using many of the training techniques in their teaching program a year later thus showing long-term retention of microteaching sessions. ${ }^{13}$

Thus, evidence from the literature clearly indicates that microteaching technique is a very efficient tool to transfer and enhance skill-based learning. ${ }^{7}$ However, until now, its use has been limited to applications in improving teaching skills or in business sector and minimally utilized in health sector. As there is enough evidence that microteaching is an effective tool for enhancing skills, we believed that it can be a potential tool to improve the skills required to deliver home-based care. Thus, a pilot study was carried out to utilize the microteaching technique for enhancing the postnatal care skills of health workers (HWs) and also to ascertain the feasibility of using the microteaching technique as a tool for supportive supervision of HWs.

\section{Methods \\ Design}

A longitudinal study design was used where postnatal skills were assessed at baseline and after each round of microteaching.

\section{Study area}

This pilot study was conducted in one of the health posts of the Department of Community Medicine, School of Public Health, Post Graduate Institute of Medical Education and Research at Urban, Community Health Center, Sector 45, Chandigarh, from August 2013 to December 2014. It caters to a population of 93,151 (urban - 29,452, rural - 36,060, and slum - 27,639).

\section{Participants}

All the HWs, that is ANMs ( $\mathrm{n}=12)$, catering to this population were recruited in this study. A lady health visitor (LHV) and a male social worker were trained to impart microteaching. Each ANM caters to $\sim 8,000$ population in the catchment area.

\section{Data collection}

As a first step, a baseline assessment of HWs was done on the skills pertaining to home-based postnatal care. Postnatal care rendered by the HWs was video recorded during their routine home visits. Written informed consent was taken from the family as well as the HWs regarding audio and video recording. It was conveyed to all the HWs that results of this study will be used only to enhance their skills and no punitive action would be taken so that they were more comfortable and willing to participate in the study. Selection of household for postnatal care was done randomly for each HW from a list of eligible beneficiaries to avoid selection bias.

A pretested structured checklist was prepared based on home-based postnatal care guidelines issued by Ministry of Health and Family Welfare, Government of India, in 2011, for recording the findings of each HW and assessment of skills after watching the video (Ministry of Health and Family Welfare 2011a). ${ }^{3}$ The checklist had three major domains, namely, maternal history and examination (16 items), newborn examination (13 items), and maternal counseling (six items). The detailed items in the checklist are listed in Table S1. Each question was scored and the final score for every HW was calculated. A score of " 0 " was given if the HW did not perform the activity/examination, " 1 " if she/he performed the activity/examination partially or incorrectly, and " 2 " if she/he performed the activity/examination correctly. Average scores were calculated for individual domains 
(maternal examination, maternal counseling, and newborn examination) and overall HW skill score was calculated by averaging the scores in each domain in each round. The scores of each round were compared to see if there is any change in the skills of HWs. In addition to a checklist, a brief interview schedule of the HWs was used to obtain information regarding years of experience of the ANM, socioeconomic status of the family visited, postnatal visit due, natal history, including birth weight, and so on.

After each round of video recording, these were shown to the HWs so that they come to know about their strengths and weaknesses. The authors filled the home-based postnatal care assessment checklist and gave scores according to the performance. The recorded videos were displayed in the classroom every week in front of HWs at a frequency of three workers per week. After the video recordings were shown to all HWs in a given round, a 1-day review and training session was organized in the class as well as at home to retrain the HWs on the gaps identified while delivering postnatal care in the videos. In order to fill the gaps in postnatal care (PNC), the right methods were demonstrated by the investigators and subsequently by the health supervisors. Each review and training session was of 90 minutes duration (15 minutes video display, 15 minutes lecture, 30 minutes demonstration of right method, 30 minutes interactive session). A Sony camcorder (Model no. DCR-SX22E, 0.8 MP camera, approximate cost Indian rupee 13,700, weighing $195 \mathrm{~g}, 60$-inch optical zoom, 2.7-inch LCD) was used for video recording. ${ }^{14}$ Video recordings and assessments followed by training continued until the HWs acquired the intended skills. Hence, a total of three rounds of video recordings were done. In the first round, a trained field investigator recorded the videos, while in the subsequent rounds program supervisors did the recordings after obtaining training. It took $\sim 2-3$ months to complete one round. The interval between training and assessment varies from 1 to 4 weeks in each round.

\section{Ethical considerations}

Prior permission to conduct this study was obtained from the Director Health Services, Chandigarh Health Administration. The institute's ethics committee of Post Graduate Institute of Medical Education and Research, Chandigarh, India, approved this study. Written informed consent was obtained from the participants to take part in the study.

\section{Data analysis}

The data were entered in Excel sheet and analyzed using Statistical Package for Social Sciences (SPSS) version 16 (SPSS Inc., Chicago, IL, USA). Proportions and mean were used to summarize variables. Analysis of variance test was used to compare scores across three rounds of microteaching.

\section{Results}

Nearly two-thirds (64\%) of the HWs were female. The mean age of HWs was 34.6 years with the age ranging from 26 to 45 years. The experience of HWs ranged from 8 months to 25 years (mean $=7.1$ years). The details of the postnatal mothers and newborns who were examined in each round are given in Table 1, which showed no significant difference in the sociodemographic and clinical characteristics across three rounds except for any comorbidity of the mother. Maternal examination skills, such as fever (0.07), discharge per vaginum (0.07), speaking abnormality/fits (0.07), leg examination $(0.07)$, breast milk $(0.21)$, breast abnormality $(0.21)$, and abdominal examination (0.29), were poor (ie, average score $<0.30$ ) in the baseline. However, they showed significant improvement in the score at the end of the third round ranging from 1.5 to 1.92 (Table 2). Maternal counseling regarding danger signs (0.43) and hand hygiene (0.14) improved significantly $(P<0.001)$ after the third round. Newborn examination of the eye (0.07), limping of legs (0.07), feeding (0.14), abdominal examination (0.0), and chest indrawing (0.0) were also poor (ie, average score $<0.30$ ) at the baseline, but showed significant $(P<0.001)$ improvement ranging from 1.50 to 1.75 at the end of the final round (Table 2).

The overall skill assessment score significantly improved with each round of microteaching from 0.64 in the first round to 1.76 at the end of the third round. Maternal examination skills improved significantly from 0.54 to 1.71 at the end of the third round. Maternal counseling skill increased from 1.01 to 1.85 at the end of the final round. After the third round, the newborn examination skills increased from 0.52 to 1.74 (Figure 1). The proportion of HWs carrying a thermometer increased markedly from $21 \%$ in the baseline to $100 \%$ in the second and the third rounds. Similarly, the proportion of HWs carrying a PNC register increased from $50 \%$ at the baseline to $86 \%$ in the second round and $100 \%$ in the third round (Figure 2).

\section{Discussion}

This is the first study of its kind which employed the technique of microteaching to improve the home-based skills of postnatal care among health care workers. The study demonstrated a definite improvement in PNC skills of HWs. The review of literature reveals that microteaching has been utilized successfully in the field of medical education for improving teaching skills among medical students 
Table I Characteristics of the postnatal mothers and the newborn who were paid a postnatal visit

\begin{tabular}{|c|c|c|c|}
\hline Characteristics & Round I N (\%) & Round 2 N (\%) & Round $3 \mathrm{~N}^{*}(\%)$ \\
\hline Total & $\mathbf{N}=14$ & $N=14$ & $N=12$ \\
\hline \multicolumn{4}{|l|}{ Place of residence } \\
\hline Urban & $4(29)$ & $4(29)$ & $2(17)$ \\
\hline Rural/slum & I0 (7I) & $10(71)$ & $10(83)$ \\
\hline \multicolumn{4}{|c|}{ Term/preterm delivery } \\
\hline Term & $12(86)$ & $14(100)$ & $12(100)$ \\
\hline Preterm & $2(14)$ & $0(0)$ & $0(0)$ \\
\hline \multicolumn{4}{|l|}{ Type of delivery } \\
\hline Normal vaginal & $8(57)$ & $13(93)$ & $9(75)$ \\
\hline Caesarean & $6(43)$ & I (7) & $3(25)$ \\
\hline \multicolumn{4}{|l|}{ Place of delivery } \\
\hline Institutional & $14(100)$ & $13(93)$ & $12(100)$ \\
\hline Home & $0(0)$ & I (7) & $0(0)$ \\
\hline \multicolumn{4}{|l|}{ Low birth weight } \\
\hline Yes & $2(14)$ & $3(2 I)$ & I (8) \\
\hline No & $12(86)$ & II (79) & II (92) \\
\hline \multicolumn{4}{|c|}{ Comorbidity of the mother } \\
\hline Yes & I (7) & I (7) & $5(42)$ \\
\hline No & $13(93)$ & $13(93)$ & $7(58)$ \\
\hline \multicolumn{4}{|c|}{ Comorbidity of the baby } \\
\hline Yes & $2(14)$ & $4(29)$ & $6(50)$ \\
\hline No & $12(86)$ & $10(7 \mid)$ & $6(50)$ \\
\hline \multicolumn{4}{|c|}{ Which postnatal visit? } \\
\hline First & $0(0)$ & $0(0.0)$ & $0(0)$ \\
\hline Second & $6(43)$ & $3(2 I)$ & I (8) \\
\hline Third and above & $8(57)$ & II (79) & II (92) \\
\hline
\end{tabular}

Note: *Two health workers got transferred after the second round.

and teachers in the class room..$^{15,16}$ Similarly, other studies have demonstrated the role of microteaching in improving communication skills and instructional competence among nurses, medical graduates, and pharmacy students. ${ }^{17-20}$ Another study in India advocated the use of microteaching as a focused pedagogical method for honing dental faculty members' presentation and interpersonal skills. ${ }^{21}$

In another study, the authors utilized microteaching with the aid of video recording and discovered that the group which used the video-recording equipment had more significant progress in the mastery of teaching skills. ${ }^{22}$ However, microteaching with the aid of video recording has no precedence in improving the skills of HWs in primary health care.

Video recordings provide an authentic feedback of an HW's interaction with the subject. Microteaching provides a systematic method for analysis of these recordings for better acquisition of skills. The potential inherent in videotape recorders and microteaching techniques seems to be unique. The self-confrontation with one's own behavior creates a sense of dissatisfaction and activates the need for self-fulfillment, which leads to better performance..$^{23}$

In this study, certain key skills in maternal examination (checking for breast abnormality, examination of abdomen and perineum, temperature recording), newborn examination (checking for jaundice, examination of eye and skinfolds, temperature recording), and maternal counseling (hand hygiene) showed marked improvement during microteaching rounds. Maternal examination skills, such as breastfeeding and bleeding per vaginum (PV) and maternal counseling related to immunization, application on cord, and referral and newborn skills, such as taking weight of the baby, showed no significant improvement, although at the end of round 3 the skill score ranged from 1.11 to 2.0 . This is probably because the HWs fared well in these skills in round 1 itself.

The present study experience showed that there are minimal technical problems regarding equipment and maintenance. It was found that there was no objective need for skilled manpower to operate the video equipment. It was also possible to record videotape with minimum disturbance to the HW and the subject's family. The video recording need not require a professional videographer; rather the HW's supervisor was trained to do the video recording. Apart from the first round which was done by the project staff, the other two rounds of recording were done by the health supervisor. The video equipment used was affordable, light weight, compact, and easy to operate. Thus, microteaching using video equipment was technically feasible at the primarycare level. 
Table 2 Scores of different domains of postnatal care in three rounds of microteaching

\begin{tabular}{|c|c|c|c|c|}
\hline Domains of postnatal care & Round I & Round 2 & Round 3 & $P$-value \\
\hline \multicolumn{5}{|l|}{ Maternal examination } \\
\hline Dietary intake & 0.67 & 1.38 & 1.92 & 0.005 \\
\hline Bleeding PV & 1.11 & 1.46 & 1.83 & 0.17 \\
\hline Keeping baby warm & 0.64 & 1.54 & 1.92 & 0.02 \\
\hline Breastfeeding & 1.93 & 2.0 & 1.92 & 0.41 \\
\hline Urination & 0.93 & 1.61 & 1.83 & 0.005 \\
\hline Fever & 0.07 & 0.69 & 1.50 & $<0.001$ \\
\hline Discharge PV & 0.07 & 0.38 & 1.58 & $<0.001$ \\
\hline Speaking abnormally/fits & 0.07 & 0.62 & 1.92 & $<0.001$ \\
\hline Breast milk & 0.21 & 0.92 & 1.67 & 0.02 \\
\hline Breast abnormality & 0.21 & 0.61 & 1.42 & 0.004 \\
\hline Abdominal examination & 0.29 & 0.46 & 1.25 & 0.004 \\
\hline Examination of the perineum & 0.79 & 1.23 & 1.75 & 0.01 \\
\hline Leg examination & 0.07 & 0.85 & 1.67 & $<0.001$ \\
\hline Average maternal examination skill score & 0.54 & 1.06 & 1.71 & $<0.001$ \\
\hline \multicolumn{5}{|l|}{ Newborn examination } \\
\hline Eyes & 0.07 & 1.08 & 1.75 & 0.001 \\
\hline Weight & 1.86 & 2.0 & 2.00 & 0.15 \\
\hline Temperature by using thermometer & 1.0 & 1.92 & 2.00 & 0.003 \\
\hline Examination of skin for pustules & 0.36 & 1.69 & 2.00 & 0.005 \\
\hline Skinfold examination for cracks or redness & 0.36 & 1.46 & 2.00 & $<0.001$ \\
\hline Jaundice & 0.64 & 2.0 & 2.00 & 0.001 \\
\hline Check umbilicus & 1.5 & 2.0 & 2.00 & 0.22 \\
\hline Limping of legs & 0.0 & 0.15 & 1.42 & $<0.001$ \\
\hline Feeding & 0.14 & 1.23 & 1.67 & 0.005 \\
\hline Cry of the baby & 0.36 & 1.15 & 1.67 & $<0.001$ \\
\hline Abdomen examination & 0.0 & 0.77 & 1.50 & 0.002 \\
\hline Chest indrawing & 0.0 & 0.0 & 1.50 & 0.005 \\
\hline Average neonatal examination skill score & 0.52 & 1.29 & 1.74 & $<0.001$ \\
\hline \multicolumn{5}{|l|}{ Maternal counseling } \\
\hline Nutrition & 1.07 & 1.77 & 1.92 & 0.05 \\
\hline Danger signs & 0.43 & 1.38 & 1.92 & $<0.001$ \\
\hline Family planning & 1.29 & 1.61 & 1.83 & 0.06 \\
\hline Immunization & 1.14 & 1.54 & 1.67 & 0.14 \\
\hline Hand hygiene & 0.14 & 1.46 & 1.67 & $<0.001$ \\
\hline Apply on cord & 1.5 & 1.92 & 1.92 & 0.10 \\
\hline Referral & 1.5 & 1.92 & 2.0 & 0.10 \\
\hline Average maternal counseling skill score & 1.01 & 1.66 & 1.85 & $<0.001$ \\
\hline Overall skill assessment score & 0.64 & 1.27 & 1.76 & $<0.001$ \\
\hline
\end{tabular}

Note: $P<0.05$ denotes significant difference.

Abbreviation: $\mathrm{PV}$, per vaginum.

Round 1

Round 2

Round 3

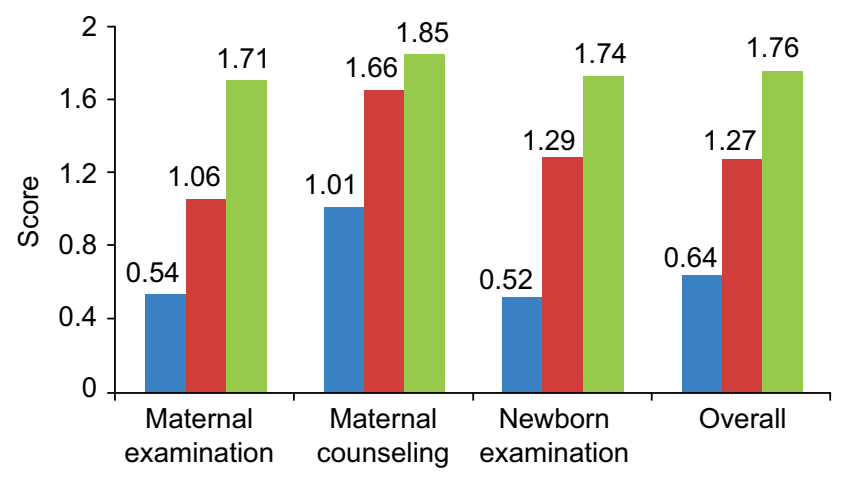

Postnatal skills

Figure I Comparison of postnatal skill score across three rounds of microteaching.
Microteaching provides experts with supervision and constructive feedback. It provides for repeated practice without adverse consequences to the trainees. ${ }^{24}$ Therefore, microteaching using video recording can be used as an efficient tool for supportive supervision and a vehicle for continuous training and skill development among primary health care workers. In another study which piloted microteaching sessions in an Indian medical school, the technique found favor among the health care workers. They also found this kind of constructive feedback more acceptable and less offensive than criticism..$^{25}$ This technique has also been shown to be effective in teaching students and teachers in medical schools. ${ }^{26,27}$ Compared to conventional training, microteaching has been proven to be effective in terms of long-term retention of 


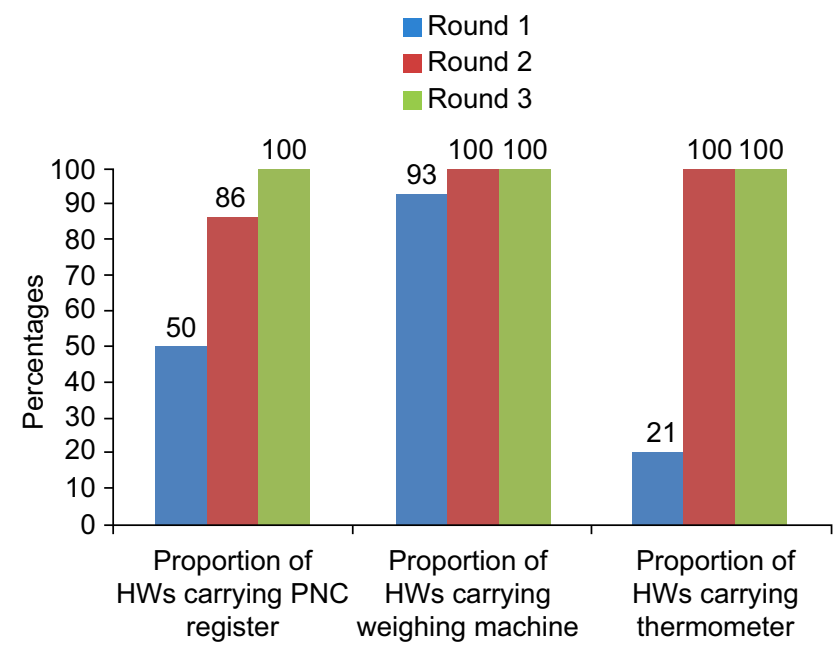

Figure 2 Comparison of PNC across three rounds of microteaching. Abbreviations: HWs, health workers; PNC, postnatal care.

learning, consuming much less time, and minimal logistic issues. ${ }^{12,24}$ Some other studies have also shown that apart from immediate effect posttraining, microteaching has been shown to demonstrate long-term retention of learned behaviors. ${ }^{13,28}$

The results of this pilot study have shown that microteaching using video recording is an effective technique for improving home-based postnatal care skills of the health care workers and a feasible option for supportive supervision. This supervisory tool has public health implications in terms of scaling it up in routine program settings to improve mother and newborn survival. ANMs may be trained to record videos of ASHA workers during home-based postnatal visits. A single recording of PNC takes around 25-30 minutes. Such videos can also be used to train health staff in postnatal care at the subcenter or primary health care center. There will be no travel cost implications as ASHAs routinely travel to these facilities. The training can be done as part of their on-job training and supportive supervision ASHAs can be shown the videos (videos of two ASHAs in each meeting; around 24 ASHAs in a year) so that everyone is covered at least once in a year. Each ANM will be required to record one video once in 2 months, which would not put additional pressure on her routine schedule. The recording device may be kept in the possession of the LHV. The ANM will collect the recording device from the LHV when she visits the subcenter during her supervisory rounds. The LHV shall prepare an annual roster for recording of videos. It may also serve as a useful learning experience for other ASHAs, ANMs, LHVs, and other staff attending the meeting. Further, once this mechanism is put in place, it may be used to improve other skills of the HWs and may not be limited to postnatal care.

\section{Limitations}

One of the limitations could be "Hawthorne effect," as HWs would perform better in front of camera as compared to what they would actually practice. This might explain more HWs carrying a weighing scale, thermometer, and PNC register. Routine supportive supervision using microteaching will ensure long-term compliance. Another major limitation in this study is that only $12 \mathrm{CHWs}$ were assessed. Hence, it is difficult to draw conclusions based on this small sample size. Therefore, it is suggested to conduct large scale community-based studies to fully realize the potential of this technique in imparting skills to health professionals. As HWs' skills were assessed within a few months time following training, long-term retention of these skills needs to be assessed in future studies. However, the present study was conducted in a mix of urban, rural, and slum setting with poor health and socioeconomic indicators. The effectiveness of microteaching in such a setting probably implies that it can be successfully replicated in other settings.

\section{Conclusion}

The results of this pilot study showed that microteaching using video recording is an effective technique for improving home-based postnatal care skills of the health care workers and a feasible option for supportive supervision. This supervisory tool has public health implications in terms of scaling it up in routine program settings to improve maternal and newborn survival. However, its full potential in largescale community-based studies needs to be investigated in imparting skills to health professionals before its use in routine program setting.

\section{Acknowledgments}

The authors are thankful to Dr Krishna Chaudhary, Senior Medical Officer, Urban Community Health Center, Sector 45, Chandigarh, for supporting them in carrying out this study. The study was funded by PGIMER intramural research scheme.

\section{Author contributions}

All authors made substantial contributions to conception and design, acquisition of data, or analysis and interpretation of data; took part in drafting the article or revising it critically for important intellectual content; gave final approval of the version to be published; and agree to be accountable for all aspects of the work.

\section{Disclosure}

The authors report no conflicts of interest in this work. 


\section{References}

1. SRS Bulletin. Sample Registration System. Registrar General of India 2014; Volume 49, No.1.

2. SRS Bulletin. Special Bulletin on Maternal Mortality in India 2010 2012. Registrar General of India 2013.

3. Home Based Newborn Care Operational Guidelines. Ministry of Health and Family Welfare. Government of India 2011. Available from: http://www.nihfw.org/Doc/NCHRC-Publications/Operational\%20 Guidelines $\% 20$ on $\% 20$ Home $\% 20$ Based $\% 20$ Newborn $\% 20$ Care $\% 20$ $\% 28 \mathrm{HBNC} \% 29$.pdf. Accessed January 15, 2015.

4. Operational Guidelines for Implementation of Integrated Management of Neonatal and Childhood Illness (IMNCI). Ministry of Health and Family Welfare. Government of India. Available from: http://mohfw. nic.in/WriteReadData/1892s/209730261RCH\%20IMNC.pdf. Accessed January 22, 2015.

5. Venkatachalam J, Kumar D, Gupta M, Aggarwal AK. Knowledge and skills of primary health care workers trained on integrated management of neonatal and childhood illness: follow-up assessment 3 years after the training. Indian J Public Health. 2011;55(4):298-302.

6. Allen DW, Ryan KA. Microteaching.Reading, MA: Addision-Wesley Publishing Company; 1969.

7. Remesh A. Microteaching, an efficient technique for learning effective teaching. J Res Med Sci. 2013;18(2):158-163.

8. Gorgen I. The influence of microteaching applications on the perspectives of pre-service teachers regarding in-class lectures and discussions. J Hacettepe Univ Educ Fac. 2003;24:56-63.

9. Seaton HW, Joseph M. Microteaching: a proposal for manpower development and training improvement. J Employ Couns. 1974;11(2): 85-88.

10. Gordon EM, Pace RW. What effects do practice and video feedback have on the development of interpersonal communication skills? J Bus Commun. 1989;26(2):159-176.

11. Takande AM, Vilhekar KY. Neonatal resuscitation training programme, its efficiency at rural hospital. Med J Islamic World. 2012;20(1):6-9.

12. Kallenbach WW, Gall MD. Microteaching versus conventional methods in training elementary intern teachers. J Educ Res. 1969;63(3): 136-141.

13. Bahar-Ozvaris S, Aslan D, Sahin-Hodoglugil N, Sayek I. A faculty development program evaluation: from needs assessment to long-term effects, of the teaching skills improvement program. Teach Learn Med. 2004;16(4):368-375
14. Sony India. HandyCam ${ }^{\circledR}$ Camcorder-Flash/Memory Stick Model: DCRSX22E/B. Available from: http://www.sony.co.in/product/dcr-sx22e. Accessed January 12, 2015.

15. Sana EA. Improving teaching through microteaching. Ann Acad Med Singapore. 2007;36(6):452-453.

16. Perrott E. Changes in teaching behaviour after participating in a selfinstructional microteaching course. Educ Media Int. 1976;13(1):16-25. Available from: http://dx.doi.org/10.1080/09523987608549188. Accessed January 10, 2015.

17. Allen ME, Belzer JA. The use of microteaching to facilitate teaching skills of practitioners who work with older adults. Gerontol Geriatr Educ. 1997;18(2):77-86.

18. Higgins A, Nicholl $\mathrm{H}$. The experiences of lecturers and students in the use of microteaching as a teaching strategy. Nurse Educ Pract. 2003;3(4):220-227.

19. Noordman J, van der Weijden T, van Dulmen S. Effects of videofeedback on the communication, clinical competence and motivational interviewing skills of practice nurses: a pre-test post test control group study. J Adv Nurs. 2014;70(10):2272-2283.

20. Popovich N, Katz N. A microteaching exercise to develop performancebased abilities in pharmacy students. Am J Pharm Educ. 2009;73(4):73

21. Kamboj M, Kamboj P, George J, Jha UK. Microteaching in dental education. J Dent Educ. 2010;74(11):1243-1244.

22. Kpanja E. A study of the effects of video tape recording in microteaching training. Br J Educ Technol. 2001;32(4):483-486.

23. Perlberg A, O'Bryant DC. The Use of Video-Tape Recording and MicroTeaching Techniques to Improve Instruction on the Higher Education Level. Department of General Engineering, College of Engineering, University of Illinois; IL: 1968. Available from: http://files.eric.ed.gov/ fulltext/ED023314.pdf. Accessed January 10, 2015.

24. Ananthakrishnan N. Microteaching as a vehicle of teacher training-its advantages and disadvantages. J Postgrad Med. 1993;39(3):142.

25. Anshu D, Singh R, Narang P. Introducing microteaching sessions in an Indian medical school. Med Educ. 2009;43(11):1087-1088.

26. Baral N, Paudel BH, Das BK, Aryal M, Das BP, Jha N, Lamsal M. An evaluation of training of teachers in medical education in four medical schools of Nepal. Nepal Med Coll J. 2007;9(3):157-161.

27. Praharaj SK. Can microteaching be used for teaching postgraduate psychiatry residents in a small group? Australas Psychiatry. 2016;24(3):305-307.

28. Crosby MH. Teaching strategies: a microteaching project for nurses in Virginia. Nurs Res.1977;26(2):144-147. 


\section{Supplementary material}

Table SI Details of the examination done by the health workers under home-based care

\begin{tabular}{|c|c|}
\hline Domain of examination & Description of the examination \\
\hline \multicolumn{2}{|l|}{ Maternal examination } \\
\hline \multirow[t]{2}{*}{ Dietary intake } & Ask about mother's dietary intake: number of times mother takes full meals in \\
\hline & 24 hours, if $>4$ whether advised on adequate diet \\
\hline Bleeding PV & $\begin{array}{l}\text { How many pads are changed each day, if more than five pads whether } \\
\text { referred to hospital }\end{array}$ \\
\hline Keeping baby warm & $\begin{array}{l}\text { Whether baby is kept warm in winter season (near mother, clothed and } \\
\text { wrapped properly) }\end{array}$ \\
\hline Breastfeeding & Is baby being fed properly (at least eight times in 24 hours) \\
\hline Cry of the baby & Is the baby crying incessantly \\
\hline Urination & Is the baby passing urine less than six times a day \\
\hline Temperature & Measure and record, if more than 100 whether referred to hospital \\
\hline Discharge PV & Foul smelling discharge \\
\hline Speaking abnormally/fits & Is mother speaking abnormally/having fits \\
\hline Breast milk & $\begin{array}{l}\text { Is mother having no milk since delivery or if she perceives breast milk to be } \\
\text { less than adequate }\end{array}$ \\
\hline Breast abnormality & Cracked nipples/painful/engorged breast \\
\hline Abdominal examination & Involution of uterus \\
\hline Examination of the perineum & Condition of the stitches \\
\hline Leg examination & Swelling, signs of deep vein thrombosis \\
\hline \multicolumn{2}{|l|}{ Newborn examination } \\
\hline Eyes & Are eyes swollen or with pus \\
\hline Weight & Measurement of weight \\
\hline Temperature by using thermometer & Measure and record temperature \\
\hline Examination of skin for pustules & Look for skin filled pustules \\
\hline Skinfold examination for cracks or redness & Cracks or redness on the skin folds (thigh/neck/axilla/buttocks) \\
\hline Jaundice & Yellowish discoloration of the eyes/skin \\
\hline Check umbilicus & Check the umbilicus \\
\hline Limping of legs & Weak/floppy/limping of legs \\
\hline Feeding & Decreased/stopped feeding \\
\hline Cry & Weak/stopped \\
\hline Abdomen examination & Distended/mother say baby vomits often \\
\hline Temperature by hand & Cold to touch/temperature $>99^{\circ}$ \\
\hline Chest & Chest indrawing \\
\hline Umbilicus & Pus on umbilicus \\
\hline \multicolumn{2}{|l|}{ Maternal counseling } \\
\hline Nutrition & Diet of a lactating mother; breastfeeding frequency; burping \\
\hline Danger signs & Child vomits everything; lethargy/unconscious; convulsions; not feeding well \\
\hline Family planning & Copper-T, condoms; permanent sterilization \\
\hline Immunization & Child immunization schedule and next date of immunization \\
\hline Hand hygiene & Importance and steps of hand hygiene \\
\hline Apply on cord & Not to apply anything on cord \\
\hline Referral & Referred those who required referral \\
\hline
\end{tabular}

Abbreviation: $\mathrm{PV}$, per vaginum.

Advances in Medical Education and Practice

\section{Publish your work in this journal}

Advances in Medical Education and Practice is an international, peerreviewed, open access journal that aims to present and publish research on Medical Education covering medical, dental, nursing and allied health care professional education. The journal covers undergraduate education, postgraduate training and continuing medical education

\section{Dovepress}

including emerging trends and innovative models linking education, research, and health care services. The manuscript management system is completely online and includes a very quick and fair peer-review system. Visit http://www.dovepress.com/testimonials.php to read real quotes from published authors. 